УДК 330.111

\title{
ПОВЫШЕНИЕ АДАПТИВНОСТИ ХОЗЯЙСТВЕННОГО МЕХАНИЗМА В КОНТЕКСТЕ ПОНИМАНИЯ ВЗАИМОДЕЙСТВИЯ ЭКОНОМИКИ И УСТОЙЧИВОГО РАЗВИТИЯ
}

\author{
O.М. МАЗУРЕНКО \\ аспирант кафедры «Экономика и право» \\ Белорусского национального технического университета, г. Минск
}

\begin{abstract}
Аннотация
В статье изложены основные теоретические подходы к определению сущцности категории «хозяйственный механизм», рассматриваются методы повышения адаптивности хозяйственного механизма страны и отдельных экономических систем.

Ключевые слова: хозяйственный механизм, адаптивность хозяйственного механизма, промышленная политика.
\end{abstract}

\section{Abstract}

The article describes the main theoretical approaches to defining the essence of the category of "reconomic mechanism», the methods of increasing the adaptability of the economic mechanism of the country and the individual economies.

Key words: economic mechanism, adaptability of the economic mechanism, industrial policy.

\section{ВВЕДЕНИЕ}

Государству принадлежит важная роль в формировании рыночной экономики и обеспечении ее эффективного функционирования. Даже в странах, где официально провозглашается принцип невмешательства государства в хозяйственные процессы (например, в США), на деле оно активно влияет на развитие экономики. Особенно это относится к природопользованию, где диапазон государственного воздействия может быть весьма широким - от прямого административного принуждения до формирования институциональных условий рыночного саморегулирования тех или иных областей природопользования.

Государственное регулирование и управление экономикой и ее отдельными структурными звеньями осуществляется с помощью хозяйственного механизма, выполняющего функции: обеспечения взаимосвязанности и сбалансированности всех структурных элементов общественного производства как целостной системы; согласования экономических интересов общества, коллективов, каждого работника, отдельных предпринимателей; воплощения на практике экономической политики государства, его стратегических целей и тактических задач.

\section{РЕЗУЛЬТАТЫ И ИХ ОБСУЖДЕНИЕ}

Современная трактовка категории «хозяйственный механизм» является результатом научных исследований, которые проводились в течение достаточно длительного промежутка времени. В настоящее время в Республике Беларусь в ряде случаев используется подход к определению хозяйственного механизма, который был выработан еще в 70-80-е годы XX века.

Значительный вклад в разработку теории хозяйственного механизма внесли такие выдающиеся ученые как Л.И. Абалкин, П.Г. Бунич, Я. Кронрод, Г. Аристов, 
В.А. Медведев, Г.Х. Попов, О. Курно, Н. Кондратьев и др. Попытки применения термина хозяйственного механизма в аналитических целях, а также существование множества авторских подходов к его определению создают предпосылки различного трактования данного понятия, несущие в себе различную смысловую нагрузку [1 - 6]. В работах В.К. Черняка хозяйственный механизм определяется как механизм использования экономических законов посредством конкретных хозяйственных и организационных форм в стране [1]. В работах А.Н. Радзиевкого [7] хозяйственный механизм рассматривается как сложная многоступенчатая иерархическая система управления экономикой страны. В то же время Д. Дудник отмечает, что наиболее корректно было бы разделять понятия «управление» и «хозяйственный механизм». По его мнению, несмотря на наличие тесной связи между хозяйственным механизмом и функциями управления, содержание понятия хозяйственного механизма не является только хозяйственным управлением [8]. Дудник указывает на тот факт, что понятие хозяйственного механизма целесообразно рассматривать в узком и широком смысле: в широком смысле хозяйственный механизм может быть рассмотрен в контексте функционирования экономической системы в целом, в узком смысле хозяйственный механизм - с точки зрения функционирования хозяйственного процесса или отдельно взятой системы управления хозяйственным процессом. Используя подход по определению структуры и сущности хозяйственного механизма, предложенный Д. Дудником можно выделить уровни экономической системы (от экономики страны до отдельно взятого рабочего места), на которых целесообразно использовать понятие хозяйственного механизма. По его мнению хозяйственный механизм - это «сложный динамический организационно-технический и социально-экономический единый производственно-хозяйственный комплекс, непрерывно функционирующий с целью выполнения государственного плана на основе сочетания централизованного руководства, хозяйственной самостоятельности, инициативы коллектива...» [9].

В своем исследовании А.Д. Дудник указывает на то, что первым исследователем, достаточно подробно описавшим схему хозяйственного механизма, является П. Бунич, общетеоретические положения которого могут быть использованы для определения структуры хозяйственного механизма при любой трактовке его сущности [10]. В своей модели хозяйственного механизма Бунич выделяет:

- «...общие функциональные подсистемы (планирование, стимулирование и ответственность, управление, социальные рычаги управления и др.).

- специальные функциональные подсистемы (научно-технический прогресс, качество продукции, внешнеэкономические связи, рациональное природопользование).

- подсистемы обеспечения (организационное, информационное, правовое, кадровое, материальное, методологическое, финансовое обеспечение)...» [10].

Достаточно широкие положения П. Бунича о том, что включает в себя хозяйственный механизм позволяют определить в структуре хозяйственного механизма элементы, которые можно описать с помощью качественных и количественных показателей. К качественным показателям следует отнести такие элементы как планирование, управление, стимулирование, развитие научно- технического прогресса и уровня внешнеторговых связей. К количественным - подсистемы обеспечения кадрами, информацией, материально-техническое снабжение, финансовое обеспечение.

Рассмотренные подходы к трактовке категории «хозяйственный механизм» должны применяться комплексно, а понятие хозяйственного механизма носить более широкий характер и не сводиться только к определению эффективности и экономического эффекта.

Процессы глобализации, оказывающие влияние практически на все страны, оказывают влияние и на хозяйственные механизмы отдельных стран и их составные элементы. 
Значимое влияние на содержание хозяйственного механизма оказывает степень обеспеченности страны природными ресурсами и иными факторами производства, включая трудовые и финансовые ресурсы, а также поставленными перед экономической системой целями и задачами, что обуславливает необходимость определения наиболее эффективных направлений и способов развития экономического механизма. Факт того, что инновационное развитие является приоритетным направлением в Республике Беларусь на сегодняшний день, обусловливает необходимость учета влияния на хозяйственный механизм и экономический результат его функционирования таких факторов производства как информация, технология, авторские права, научные исследования и разработки, используемых в практике хозяйственной деятельности предприятий.

В качестве основы методологической базы по управлению отдельными элементами хозяйственного механизма в Республике Беларусь может быть выделено проведение организационных мероприятий по формированию промышленной политики. При этом при формировании промышленная политика в содержательной части не сводится только к эффективности управления хозяйственным механизмом, но также является отдельным элементом, оказывающим влияние на структурные преобразования в экономике страны и хозяйственном механизме [11]. В рамках рассмотрения вопроса определения теоретико-методологических основ формирования хозяйственного механизма в Республике Беларусь целесообразно раскрыть его адаптивность.

Проблема адаптивности хозяйственного механизма республики к изменению условий на внутреннем и внешних рынках является одной из фундаментальных проблем экономической науки. Повышение (либо сохранение) качественных характеристик экономической динамики является ключевой задачей экономической политики любого государства, в том числе и Республики Беларусь. Этот вопрос лежит в основе всех успешных и неудачных попыток модернизации хозяйственного механизма, охватывающих широкий спектр преобразований на макроэкономическом уровне и уровне малых экономических систем (предприятий и домохозяйств). Исследование феномена адаптивности в контексте понимания взаимодействия экономики и устойчивого развития открывает возможности продуктивной корректировки целей экономического развития и выработки механизмов их реализации, адекватных реалиям XXI века.

Исходные идеи адаптивности были заимствованы из биологии. Исследования базовых свойств экономических и биологических систем (проведенные междисциплинарной научной группой в Институте Санта-Фе (SFI)) позволили обнаружить схожие закономерности в их эволюции. Это позволило распространить на экономику алгоритмы адаптации к изменениям внешней среды, присущие биологическим системам, и трактовать их как универсальные принципы эволюции живых систем. Адаптация, рассматриваемая в контексте теории эволюции, представляет собой свойство системы изменять свое поведение и структуру, и тем самым успешно противостоять воздействию внешней среды. Критерием успешной адаптации системы является ее жизнеспособность, ее повышение по мере изменения окружающей среды. Базовые принципы адаптивности обладают значительным методологическим потенциалом, способным послужить основой выработки новых стратегий развития экономических систем разного уровня. В условиях экономики становящейся все более глобальной и нестабильной, растущей взаимозависимости рынков и технологий адаптироваться к любым изменениям превращается в «критерий истины» активности всякого хозяйствующего субъекта, определяющий его шанс на выживание и перспективы развития. Это свойство становится ключевым проявлением качества функционирования и развития любой системы: будь то предприятие, отрасль, национальная экономика. Новые реалии превращают способность к адаптации в главный критерий качества экономического роста, как интегративного проявления гибкости домохозяйств, предприятий и национальноэкономических комплексов. Важнейшим показателем устойчивости хозяйственного 
механизма становится его адаптивность к внешним и внутренним шокам.

Можно утверждать, что в некоторой степени «ген адаптивности», предопределяющий конфликт с непредсказуемыми реалиями сегодняшнего дня, присущ малым экономическим системам. Значительная часть действующих сегодня предприятий относительно консервативны в применяемых технологиях, выпускаемой продукции, занимаемых рыночных нишах, принципах организации производства и хозяйственных связей, системах менеджмента. Их динамика отстает от изменений окружающего мира. Новые условия потребовали от корпораций приобретения необходимой гибкости и существенного сокращения издержек.

Недостаточность инноваций в экономике XXI века вызывает поиск путей разрешения конфликта малых экономических систем с внешней средой своего существования. Качественно иной уровень конкуренции, предполагающий постоянное появление новых конкурентов, внедряющих передовые технологии и приемы сокращения затрат, требует от предприятий не столько рутинной экономии, сколько кардинального повышения эффективности. Необходимо обеспечение высочайшей техникотехнологической гибкости производств, позволяющей экономическим системам быстро переключаться на новые виды продукции, технологически обновляться, разворачивать и свертывать производство, перемещать его территориально. Универсальность оборудования, возможность его рекомбинации, легкость и модульность сооружений и т. п. позволяют современным предприятиям быстро возникать в определенном месте и при необходимости так же быстро покидать его.

Другой аспект микроэкономической адаптивности связан с возможностью быстро обновлять выпускаемую продукцию, переключаться на иные ее виды, расширять номенклатуру продукции и, в конечном счете, менять нишу бизнеса. Эти проявления диверсификации производства носят циклический характер. В истории большинства ведущих корпораций мира есть периоды доминирования специализации и «увлечения» диверсификацией деятельности, когда развитие фирмы приобретает конгломератный характер. Диверсификация производств позволяет предприятию, в условиях нарастающей неопределенности экономических процессов и угасающей доходности традиционных сфер деятельности, нащупывать новые перспективные сферы деятельности, обеспечивающие высокую прибыль точки притяжения инвестиций.

Одним из ключевых моментов адаптивной способности является гибкость в использовании трудовых ресурсов. Сегодня это одна из самых консервативных и проблемных сторон деятельности предприятий. Социальные обязательства, регламентируемые совокупностью правовых норм и регулируемое государственными и негосударственными институтами, не только подрывает экономическое положение предприятий передовых стран, но и затрудняет адаптивную трансформацию производств. Повышение гибкости в использовании труда становиться условием выживания фирмы. Увеличение мобильности труда затрагивает все категории работников и меняет структуру персонала современных корпораций. В ней все более четко проявляется различие между кадровым ядром, сохраняемым корпорацией, и так называемой «располагаемой рабочей силой». Последняя представляет собой подвижный контингент, который можно заменить автоматизацией, привлечь извне в зависимости от рыночного спроса на труд и потребности предприятия в трудовых ресурсах. Гибкость в использовании трудовых ресурсов, охватывающая все сегменты рабочей силы, связанная с привлечением рабочей силы извне, распространением практики аутсорсинга, является следствием возникновения сетевых форм организации бизнеса.

Обязательным условием успешного функционирования предприятия в новых условиях является его интитуциональная адаптивность. Речь идет не только о его институциональном устройстве (т.е. организации отношений собственности, формах хо- 
зяйствования, распределении управленческих полномочий и др.), но и о состоянии институциональной среды своего существования. Институциональная эластичность позволяет предприятиям быстро менять организационную форму своей деятельности, трансформироваться, распадаться на части и собираться в крупные хозяйственные структуры.

В настоящее время проблемы развития производства требуют пристального внимания. Сегодня развитие хозяйственного механизма в целом и промышленности в частности является основополагающим условием сохранения государственного суверенитета, экономической безопасности страны. Наиболее эффективным инструментом воздействия на хозяйственный механизм является промышленная политика.

Под термином промышленная политика понимается вся совокупность мер экономической политики государства, способствующих развитию промышленности. В основе этого подхода лежит фактический отказ от любых попыток сформулировать и реализовать на практике специфический комплекс мер, направленных на развитие исключительно промышленных секторов и соответствующих им видов предпринимательской деятельности. В качестве стратегической цели промышленной политики следует рассматривать создание технологически современного, конкурентоспособного хозяйственного механизма на основе комплексной модернизации основных производственных фондов, а точнее формирование и развитие производств пятого и шестого технологических укладов, стимулирование их роста.

В качестве тактических целей на краткосрочную перспективу можно предложить: создание общественно-государственного механизма реализации промышленной политики (эффективное взаимодействие органов государственного управления и социальнонаучного сообщества и адекватных политико- экономических институтов и т.д.); целенаправленную конфигурацию, преимущественно институциональными методами, рыночных механизмов обеспечения ресурсной базы технологического перевооружения отечественной индустрии; формирование современной системы государственной поддержки экспорта, в том числе за счет формирования развитых товаро-проводящих сетей; формирование стимулирующей налоговой системы; создание системы стимулирования производства наукоемкой продукции, в том числе за счет целенаправленного развития венчурного финансирования и т.д.

\section{ВЫВОДЫ}

С помощью промышленной политики необходимо определить ряд важных параметров: обозначить рынки, за счёт которых планируется реализовывать экономический рост (преимущественно внутренний рынок; ориентирование на экспорт); определить отраслевую структуру, на базе которой осуществиться экономический рост; определить источники и ресурсы роста, а также процесс их мобилизации и использования; определить субъекты модернизации и механизмы мотивации каждого.

\section{ЛИТЕРАТУРА}

1. Противоречия социалистической собственности и перестройка хозяйственного механизма : Монография / С. В. Мочерный, М. И. Долишний, В. К. Черняк ; под ред. С. К. Мочерного. -Львов : Свит, 1991. - 239 с.

2. Братищев, И. М. Социальная рыночная экономика и механизм становления в России / И. М. Братищев. - М. : Экономика, 2003. - 216 с.

3. Бурков, В. Г. Механизмы управления / В. Г. Бурков. - М. : Ленанд, 2011. - 192 с.

4. Измалков, С. Теория экономических механизмов / С. Измалков // Вопросы экономики. - 2008. - № 1. - С. 4-26. 
5. Абалкин Л.И. Хозяйственный механизм развитого социалистического общества. М., 1973.

6. Кульман, А. Экономические механизмы : пер. с фр. / А. Кульман ; общ. ред. Н. И. Хрусталевой. - М. : Прогресс : Универс, 1993. - 192 с.

7. Радзиевский А.И. Централизация и самостоятельность. Отраслевой аспект / А. И. Радзиевский; рец.: А. Ф. Сильченков, Л. Н. Рожков. - 1987.

8. Хозяйственный механизм: сущность и структура / А. Д. Дудник. - Киев : о-во «Знание» УССР, 1983. - 18 с. : схем.; 20 см. - (Шк. хоз. управления. / О-во "Знание" УССР).

9. Дудник А. Д. Развитие хозяйственного механизма на современном этапе. К.: Знание, 1980.

10. Бунич П. Г. Хозяйственный механизм развитого социализма. М., 1980.

11. Постановление Совета Министров Республики Беларусь от 5 июля 2012 г. № 622 «Об утверждении программы развития промышленного комплекса Республики Беларусь на период до 2020 года» [Электронный ресурс] // Режим доступа: http://research.bsu.by/wp-content/uploads/2014/10/postanovlenie-sm-622-5.07.2012-red30.06.2014.pdf. - Дата доступа: 12.12.2015.

Статья поступила в редакиию 23 декабря 2015 года. 